\title{
La Construcción de Metáforas y Adjetivaciones sobre la Enfermedad en la Prensa Escrita: el caso de la epidemia de dengue en Córdoba durante abril de 2009'
}

The Construction of Metaphors and Adjectivations about Disease in the Press: the case of the dengue epidemic in Cordoba during April 2009

\author{
Raquel Irene Drovetta \\ Doctora en Antropología Social. Centro de Estudios Avanzados- \\ Unidad Ejecutora de CONICET. Universidad Nacional de Córdoba. \\ Integrante del Programa de Investigación "Sociedad, Salud, \\ Enfermedad y Prácticas de curar" del CEA/UE-UNC. \\ Dirección: Av. General Paz 154-2 piso. CP 5000. Córdoba, Argen- \\ tina. \\ E-mail: raqueldrovetta®cea.unc.edu.ar

\section{Martín Eynard} \\ Doctorando en Ciencias Sociales y Humanas. Centro de Estudios \\ Avanzados-Unidad Ejecutora de CONICET. Universidad Nacional \\ de Córdoba. Integrante del Programa de Investigación "Sociedad, \\ Salud, Enfermedad y Prácticas de curar" del CEA/UE-UNC. \\ Dirección: Av. General Paz 154-2 piso. CP 5000. Córdoba. \\ E-mail: meynardळconicet.gov.ar \\ I Esta investigación se enmarca en el Proyecto de Investigación \\ Plurianual (PIP) 2010-2012, financiado por Consejo Nacional de \\ Ciencia y Técnica (CONICET) "Enfermedad y políticas de salud en \\ Argentina. Dolencias transmitidas por mosquitos desde la fiebre \\ amarilla hasta el dengue. 1871-2009".
}

\section{Resumen}

Durante abril de 2009 emergió en la ciudad de Córdoba (Argentina) el fenómeno del dengue en la medida en que fue ese periodo temporal el que desató la primera serie de casos autóctonos. Sociológicamente, resulta de interés rescatar los diversos significados que circularon en torno a la enfermedad, ya que muestran indicios sobre las marcas que se dieron en los albores de la epidemia. El objetivo del trabajo fue analizar la construcción mediática que hizo el periódico "La Voz del Interior" (versión digital) en torno a tres tópicos en particular: el dengue, los afectados por la enfermedad y el rol del Estado, en la Ciudad de Córdoba y en el período aludido. Metodológicamente, se analizaron las noticias vinculadas al dengue, con el objetivo de identificar la construcción mediática desde el matutino en cuanto a los tres tópicos mencionados. Se generaron categorías descriptoras a través del "método comparativo constante" (Glaser y Strauss, 1967). Sintéticamente, las conclusiones indicaron que el dengue fue entendido como: a) enemigo "guerrilla", b) error o sorpresa y c) re-distribuidor de riesgos. En segundo lugar, el Rol del Estado fue entendido como un estado "activo" (positivo) o como uno "inactivo" (negativo), diferenciándose en sus tres órbitas (Municipal, Provincial y Nacional) Asimismo, los potenciales afectados fueron categorizados como: a) responsables, b) víctimas del Estado y c) precavidos-ignorantes. Además, hubo un fenómeno 


\section{de invisibilización del dengue por el "efecto Gripe A (H1N1)" a partir del 28 de abril del 2009. Finalmente, se plantearon nuevos interrogantes para indagar en futuras investigaciones.}

Palabras clave: Dengue; Medios de Comunicación; Salud; Enfermedad; Estado.

\section{Abstract}

During April 2009, the phenomenon of dengue emerged in the city of Cordoba (Argentina). It was in this period that the first wave of autochthonous cases was triggered. Sociologically, it is interesting to investigate the various meanings that circulated around the disease, as they signal the marks that were given at the beginning of the epidemic. The objective of this study was to examine the media construction made by the newspaper "La Voz del Interior" (digital version) on three topics in particular: dengue, the ones affected by the disease and the role of the State, in the city of Cordoba and in the above-mentioned period. As for the methodology, we analyzed the news related to dengue, with the aim of identifying the media construction of the daily newspaper regarding the three mentioned topics. Descriptive categories were generated through the "constant comparative method" (Glaser and Strauss, 1967). In summary, the findings indicated that the disease was understood as: a) "guerrilla" enemy, b) error or surprise, c) risk re-distributor. Secondly, the Role of the State was seen as an "active" State (positive) or as an "inactive" (negative) one, differing in its three orbits (Municipal, Provincial and National). The potentially affected people were categorized as: a) responsible, b) victims of the State c) cautiousignorant. There was also a phenomenon of invisibilisation of dengue by the "Influenza A ( $\left.\mathrm{H}_{1} \mathrm{~N}_{1}\right)$ effect" from April 28, 2009, onwards. Finally, new questions emerged to be investigated in future research.

Keywords: Dengue; Media Health; Disease; State. 


\section{Introducción}

Durante el mes de abril de 2009 emergió con fuerza en la ciudad de Córdoba una epidemia de dengue, generándose notorias repercusiones tanto para la sociedad local como para los medios de comunicación. La aparición en escena de un fenómeno epidemiológico de este tipo fue considerado novedoso, dado que la provincia mediterránea no contaba con antecedentes en la emergencia de este padecimiento. Esto determinó que los medios de comunicación y entre ellos específicamente el diario "La Voz del Interior" -versión electrónica- (en adelante LVI), periódico de mayor circulación en la provincia, reflejara el avance de la epidemia a través de información sobre variados aspectos de dicho fenómeno.

En la tarea de informar a los lectores, entendemos que dicho periódico también contribuyó a crear una serie de adjetivaciones y metáforas (Sontag, 2003) a través de las cuales describió la dinámica de la epidemia.

Sociológicamente, resulta de especial interés rescatar los diversos significados que circularon en torno a la dinámica de la epidemia para el período, ya que nos ofrecen indicios para comprender cómo el accionar de dichas metáforas dan cuenta de las representaciones a las que alude un medio de comunicación, en su intento por describir la realidad. En esa descripción, el periódico LVI abundó en adjetivaciones con las que definió la epidemia, y es en ese proceso de "construcción" del fenómeno donde tenemos la posibilidad de advertir, a través de un estudio de caso, las intencionalidades comunicativas de un mass media en su relación con los lectores y cómo estas impactan en las representaciones que los lectores tienen sobre los procesos de salud-enfermedad-atención.

La forma en que un medio de comunicación interpreta y editorializa una epidemia nos ofrece, además, la oportunidad de interrogarnos sobre la relación que se establece entre dicho medio y el Estado durante la emergencia de un problema de salud pública que afecta a gran parte de la sociedad. En este contexto, la prensa ha sido, históricamente, un ámbito de explicitación de supuestos, de prejuicios y de temores (Carbonetti, 1999).

Específicamente, nos enfocamos en analizar tres dimensiones: el rol del Estado, en su versión nacional, provincial y municipal; la enfermedad del dengue en sí misma y finalmente los (potenciales) afectados. Cada una de dichas dimensiones asumió particulares significados, que aunados en un interjuego semántico, dieron cuenta de cómo editorialmente un medio de comunicación interpreta y trasmite lo que considera ser la dinámica social generada en torno a un fenómeno como la epidemia del dengue. El objetivo de este trabajo se traduce entonces en identificar y describir las características que asumió la construcción mediática que hizo el periódico local LVI en su versión digital, en torno al dengue, al rol del Estado y a los (potenciales) afectados por la epidemia, durante el mes de abril de 2009 y espacialmente delimitado a la ciudad de Córdoba.

Como objetivo secundario, pretendemos también contribuir al análisis sociológico de la relación entre la producción de conocimiento científico en salud y el ámbito de la comunicación social, concientes de la importancia de "informar, influenciar y motivar a los individuos, las instituciones y al público general sobre temas de salud" (Alcalay 1999, p.192) Sabemos que los medios masivos de comunicación se han convertido en la fuente principal de información sobre la salud, función que se ha exacerbado a la luz de la epidemia global de gripe A (H1N1) Similar comportamiento presentaron los medios de comunicación en epidemias regionales, como la del dengue acontecida en la ciudad de Córdoba, donde desempeñaron un rol fundamental dentro de la sociedad, por ejemplo en la distribución de información para la prevención o disminución de riesgos de contraer padecimientos. Sin embargo, también se han convertido en fuente de consulta médica, por sobre los médicos, asumiéndose como representantes legitimados para la enunciación de normas, y en algunos momentos han contribuido a la generación de preocupaciones extremas y temores exacerbados respecto a la posibilidad de contagios masivos o en cuanto a la sospecha de que los gobiernos ocultan cifras y manipulan la información brindada. Finalmente, pretendemos mostrar cómo el rol de los mass media que informan sobre una situación sanitaria, se ve atravesado por la posición política de la editorial de la empresa, que según nuestro análisis, incide en la construcción 
de la noticia, sobre todo en aquellas donde se emite un juicio sobre el accionar del gobierno respecto de la epidemia.

\section{Metodología}

La investigación fue de perfil exploratorio, con técnicas de recolección y análisis de datos centradas en torno a la teoría fundamentada y al método comparativo constante de B. Glaser y A. Strauss (Glaser y Strauss, 1967), modelo de análisis cualitativo de datos que permite generar categorías inductivamente mediante muestreo teórico y saturación (Yuni y Urbano, 1999) Las características principales de esta propuesta son que es un modelo que sirve para "generar teoría" a partir de los datos inductivamente y no pretende llegar a generalizaciones estadísticas. Es un modelo muy fructífero para estudios exploratorios, en tanto la fiabilidad de los datos surge basándose en el criterio de "saturación" de las categorías de análisis emergentes. Esto sucede cuando no hay información adicional tendiente a generar más propiedades de la categoría en cuestión. La "saturación”, en otros términos, se refiere al punto en que "los nuevos casos ya no aportan conocimiento; se llega a esta saturación por la operación conjunta de recolección y análisis de datos" (Forni, 1993)

El trabajo con la fuente de información implicó la selección de 202 artículos periodísticos desde el sitio web ${ }^{2}$ del periódico de la ciudad de Córdoba "La Voz del Interior”, del 1 al 30 de abril de 2009, con el filtro de búsqueda "dengue" como palabra clave a buscar dentro del cuerpo de la noticia y/o en el titular de la misma y en todas las secciones y suplementos del diario. Cabe aclarar que no todas las noticias se utilizaron, dado que algunas no hacían referencia a la ciudad de Córdoba específicamente, sino a otras localidades del país.

\section{Algunos Antecedentes}

El estudio del rol que juegan los medios masivos de comunicación en las epidemias, tanto para visibilizar el fenómeno sanitario como para dar la voz legítima a los expertos y al Estado, entre otros fenómenos, tiene antecedentes en trabajos realizados por Alcalay (1999), quien rescata la importancia de resaltar la potencialidad del vinculo entre los medios de información y los generadores de conocimientos científicos en salud. Para el contexto latinoamericano, encontramos las investigaciones de Massarani y Buys (2007) donde se plasma a través de un estudio pormenorizado cómo un conjunto de medios de comunicación gráficos de Latinoamérica refleja la información que producen científicos y técnicos, mientras Mosquera y colaboradores (2006), da cuenta de la importancia de crear estrategias comunicativas tendientes a mejorar una situación epidemiología crítica como la generada por el dengue, incentivando la participación de la propia comunidad y no sólo la de los medios de comunicación.

Con relación al estudio del dengue, Caballero Hoyos y colaboradores (2006) explora, a través de un estudio de caso, las concepciones que una comunidad tiene acerca de la enfermedad del dengue como ejemplo a través del cual el Estado puede generar campañas preventivas, favoreciendo la participación comunitaria en la planificación de políticas sanitarias.

Finalmente, el trabajo de Sutter destaca en términos históricos la interesante analogía entre el discurso médico y el militar, que sugería la necesidad de entablar "una guerra contra los insectos" como forma de vencer a la enfermedad y a la naturaleza, dos obstáculos que se interponían en la construcción del Canal de Panamá a inicios del siglo XX (Sutter, 2000, p. 87)

\section{Dinámica Epidemiológica del Dengue en Córdoba}

El dengue es una enfermedad causada por un virus, transmitida de persona a persona a través de un mosquito, que es el vector de la enfermedad -el Aedes aegypti. Este mosquito tiene hábitos domiciliarios, por lo que la enfermedad es considerada predominantemente urbana (Ministerio de Salud de la Nación, 2009)

Se conoce que la re-emergencia del dengue en Argentina empezó en 1998 y desde entonces acontecieron 2.799 casos y seis brotes epidémicos corres-

2 El link para ediciones anteriores de La Voz del Interior On line es: http://buscador.lavoz.com.ar/ 
pondientes a los años 1998, 2000, 2002, 2003, 2004 y 2007. En cada caso, las provincias que notificaron la presencia de casos autóctonos fueron Salta, Jujuy, Formosa y Misiones (Argentina (Médicos del Mundo), 2009) En ese sentido, la región central del país, y particularmente Córdoba, históricamente no tuvo una "cultura del dengue" ni supo de la presencia de la enfermedad entre sus habitantes debido, entre otras variables, a su ubicación geográfica y características climáticas, menos propicias para la propagación del mosquito vector.

Esta suerte de distancia entre la enfermedad como hecho objetivo y las representaciones que la sociedad local tenía sobre la misma se constituye como un indicador que nos permite explicar las primeras reacciones sociales -generalmente negadorasante una enfermedad que avanzaba paulatinamente sobre la ciudad de Córdoba. Esta situación difirió completamente con respecto a lo que aconteció con brotes epidémicos en otros países de la región sudamericana o inclusive en zonas del norte de nuestro país, más habituados a la presencia del dengue.
Según las editoriales del periódico analizado, el 14 de abril de 2009 se habían declarado ya 43 casos "importados" 3 en la provincia de Córdoba, mientras que los primeros casos "autóctonos" fueron oficialmente reconocidos el 17 de abril. Estas fechas son importantes ya que determinaron un giro en la construcción de la noticia, que a mediados de mes se focalizaba en la ciudad de Córdoba e indicaba una mayor dedicación de espacios gráficos al tema.

La anterior contextualización sobre el padecimiento nos introduce ya a nuestro análisis, en el cual estudiamos los tres planos mencionados previamente, cada uno con sus categorías específicamente creadas a la luz del análisis de las noticias recolectadas.

\section{Análisis de las Categorías Analíticas y su Adjeti- vación}

Para el análisis de las tres dimensiones de estudio -la enfermedad, el rol del Estado y los (potenciales) afectados- se generaron, a través del método comparativo constante, una serie de categorías descriptoras de las distintas significaciones que adquirieron en la redacción periodística los elementos en cuestión.

Tabla I - Dimensiones de análisis generadas y sus categorías - significados

\begin{tabular}{ll} 
Dimensiones de análisis-categorias & Adjetivación - significados \\
El dengue & Como enemigo (guerrilla) \\
& Como error o sorpresa \\
& Como re-distribuidor de riesgos \\
\hline El rol del Estado & ACTIVO - reparador - previsor - eficiente \\
& INACTIVO - negligente - abandónico - ineficiente \\
\hline Los (potenciales) afectados & Responsables \\
& Víctimas del Estado \\
& Precavidos - ignorantes \\
\hline
\end{tabular}

\section{El dengue}

\section{El dengue como enemigo (guerrilla)}

La referencia a la enfermedad del dengue como un enemigo a vencer, abunda en la construcción semántica de las noticias analizadas. La referencia a un agente patógeno como enemigo, en una clara emulación del discurso médico y militar, no es novedosa, sino que tiene amplios antecedentes en los estudios que abordan el análisis de los procesos de salud-enfermedad-atención desde las ciencias sociales.

3 Se trata de casos identificados como "importados" por haber contraído la enfermedad fuera de su lugar de residencia, en este caso Córdoba, mientras que se denominó como "autóctonos” a los casos de personas que se contagiaron estando en la ciudad de Córdoba. 
Aquellos pioneros en la medicina tropical que actuaban en contextos epidemiológicos donde existía la malaria y la fiebre amarilla, entendían que las enfermedades de estos contextos debían ser enunciadas a través de un discurso de tipo bélico, porque la mayoría de estos médicos tenían formación militar (Caponi 2003, Sutter 2000) Esto se corresponde con un proceso de desarrollo histórico de la ciencia, que desde fines del siglo XIX, cuando se identificaron las bacterias como agentes patógenos y consecuentemente con el avance del positivismo, permitió que la medicina reforzara sus discursos naturalistas y biologicistas asumiendo características discursivas que perduran hasta hoy. Nos referimos en este caso a la frecuencia con que gran parte de las acciones terapéuticas reciben denominaciones referidas a la "metáfora militar" (Sontag, 2003, p. 31).

La particularidad en el caso que trabajamos en esta comunicación radica en la transposición acrítica del discurso médico-militar a los medios de comunicación que refieren a procesos de salud, enfermedad y atención. Específicamente para el caso que nos ocupa, LVI utilizó frecuentemente denominaciones con alusión militar en sus adjetivaciones acerca de aspectos de la enfermedad. Abundaron ejemplos como la descripción acerca del "avance" de la medicina por sobre la enfermedad, o de la enfermedad sobre la población, entre otros. Vocablos que contribuyeron a comparar el contexto epidemiológico con una situación de enfrentamiento militar donde el dengue (simbolizado en su vector) constituyó el "enemigo" a derrotar. Empero, es de destacar cómo el vocablo militar no se filtró de manera aleatoria en el relato sanitario que hizo el periódico, sino que se nutrió de un lenguaje específicamente creado para referirse a la "guerra de guerrillas"4. El comportamiento del mosquito vector, leído en clave de guerrilla ${ }^{5}$, brinda una serie de analogías por demás interesantes: hostiga al enemigo (humanos) en el propio terreno (los hogares, la ciudad) con fuerzas variables, mediante ataques rápidos y sorpresivos y se refugia en lugares inesperados o de difícil acceso (floreros, cacharros, charcos, piletas) A veces, incluso, cuenta con el apoyo de la población local (bien con el descuido sobre los cacharros, bien con las piscinas en las zonas residenciales) Las respuestas, así, serán a través de una "guerra contra los insectos" según describía Sutter (200o, p. 87) para inicios del siglo XX, lo que en la actualidad se traduce en "campañas" contra el dengue, con tácticas y estrategias convencionales (fumigaciones masivas por parte del Estado), pero también con tácticas tipo comando anti-guerrilleras, apoyando campañas domésticas de "descacharramiento" , en donde serán los grupos familiares los encargados de controlar al vector, en sus casas, por ellos mismos. Si bien Sutter hizo su pesquisa contextualizando las representaciones en torno al mosquito durante la construcción del canal de Panamá (iniciada a principios del S.XX y concluida en 1914), es por demás elocuente que este autor indique la emergencia del mosquito "en el papel del subversivo modelo" (Sutter, 2000, p. 73), lo cual coincide con la caracterización que estamos construyendo en este trabajo. A continuación, algunas citas referidas a este tema:

- "Ante el avance de los casos de dengue en el país, y la confirmación por parte de la Ministra de Salud de la Nación, Graciela Ocaña, de una muerte causada por la enfermedad en Charata en la provincia de El Chaco, en Córdoba se intensificarán en los próximos días las acciones encaminadas a eliminar a los mosquitos que la transmiten". La Voz del Interior On line (LVI) (01/o4/o9)

- "Por su calidad de provincia vecina, la situación de Catamarca preocupa especialmente a Córdoba". (LVI. 02/04/o9)

- "[El Aedes albopictus] No fue encontrado en Córdoba, pero sí está presente en el nordeste del país. Podría viajar hacia el sur" (LVI 05/o4/og)

- "[Un especialista] enfatizó el rol esencial que tiene la comunidad en la lucha contra el dengue, así como la necesidad de llevar adelante acciones continuas y sostenidas para mantener a raya al mosquito que

\footnotetext{
4 Algunos textos clásicos sobre la guerra de guerrillas abarcan a Guevara, Ernesto (1997) "La guerra de guerrillas", entre otros.

5 Si bien esta campaña fue realizada en Rio Tercero (Prov. De Córdoba) y no en la capital, el titulo de la noticia aludiendo a la campaña doméstica contra el dengue fue por demás clara: “Actualmente continúa la campaña Caza en casa”. (LVI 24/o5/o9).

6 Se trata de la acción de eliminar todo cacharro (recipiente) donde pueda acumularse agua y reproducirse el mosquito.
} 
lo transmite" (LVI o6/o4/og)

-[Se fumigará en los peajes de las Rutas 9, 19, 36] para resguardar a los camioneros que transitan cerrados con lona o cerrados tipo frigorífico y que provienen del norte, ante la amenaza del dengue [...] se está hablando con Gendarmería y con la Policía porque es un operativo que requiere de las fuerzas de seguridad". (LVI 07/o4/og).

- "El Gobierno provincial recomienda no viajar al norte" (LVI o7/o4/o9)

• "Sumarán 300 brigadistas contra el dengue" (LVI o8/o4/og).

• "El dengue ya tiene su canción” (LVI 10/o4/og)7.

- "Las patrullas del Ministerio de Salud extenderán desde el lunes el operativo al resto de los domicilios de Capital, para frenar la propagación del mosquito" (LVI 11/o4/og)

• "La batalla contra el dengue" (LVI. 21/o4/o9)

- "La ministra dice que la lucha contra el dengue "debemos darla todos y cada uno en el lugar donde estemos". (LVI 22/04/og).

- "Lo de Villa El Libertador podemos vincularlo a que en ese barrio viven muchos inmigrantes bolivianos, que viajan a su país, donde hay epidemia de dengue" (LVI 23/04/o9)

Se observa cómo en los testimonios recogidos por el diario, se reprodujeron dichos conceptos, especialmente en el caso de entrevistas a funcionarios públicos, que desarrollaban alguna tarea de responsabilidad política en esta coyuntura (funcionarios públicos en cargos jerárquicos) El funcionario público se adjudicó el rol de conductor de la lucha contra el enemigo y asumió la responsabilidad de vencerlo.
La delimitación de "fronteras" que discursivamente LVI describió, se ofrece como un plano metafórico interesante de indagar, en tanto en las noticias el dengue apareció significado como un "Otro" externo, ajeno y peligroso (un enemigo "guerrillero"), donde las tácticas y estrategias para combatirlo, asumieron homologías fecundas entre el campo militar y el médico. Aquí cobró especial relevancia la relación que se establece entre los entornos geográfico-climáticos (tropicales) que se consideran los ambientes "naturales" del dengue (norte de Argentina, Bolivia, Paraguay y en menor medida en los relatos, Brasil) y la vinculación de dichos lugares con territorios que en algún momento estuvieron vinculados a la guerrilla sudamericana en los 60 y 70 del siglo pasado. En otras palabras, sostenemos que en plano representacional, la imagen del mosquito subversivo tiene otro argumento a su favor a partir de la vinculación de los lugaresy-climas del mosquito con los lugares-y-climas de la guerrilla. Otro ejemplo de lo anterior-además de los relatos citados- sería el entorno selvático que eligió el ERP argentino para desarrollar sus actividades, a principios de los ' $70^{9}$. Ese sedimento en la memoria colectiva contribuiría a reproducir la representación del mosquito subversivo a la que hacemos alusión. En vinculación con lo anterior, pero atendiendo más a la dimensión identitario-nacional, Argentina Médicos del Mundo (2009) advertía claramente que hay que "evitar caer en reflexiones y/o declaraciones 'aberrantes' para la salud pública con enfoques que alientan la xenofobia poniendo como factor central de la epidemia del dengue a la migración de los países limítrofes".

En este sentido, la determinación de una suerte de frontera entre los espacios que ocupara la epide-

\footnotetext{
7 La canción se llama "El cuarteto del Dengue" y fue escrito por un autor anónimo cordobés llamado "El Enmascarado". El cuarteto es un género musical popular típico de la ciudad de Córdoba. El gobierno estuvo considerando la posibilidad de utilizarlo en campañas publicitarias. La canción, muy breve, dice: No dejes latas / cacharros o vasijas / donde el agua / se puede acumular. / Techos de lona, / floreros o cubiertas sin tapar, / porque el mosquito / ahí va a procrear. /// Dengue, dengue, dengue, / hay que sacar / a ese mosquito rebelde. / Dengue, dengue, dengue, / no le des oportunidad. /// Dengue, dengue, dengue, / hay que sacarlo / al mosquito del dengue. /// Dengue, dengue, dengue, / no le des chances en tu hogar.

8 El "Otro" como un agente externo y extraño también tomó la característica de ser, de alguna u otra manera, el origen de la enfermedad. Tal como indica Caballero Hoyos y colaboradores (2006) aparece también la higiene como mecanismo diferenciador de la comunidad cercana (limpia) frente a personas y comunidades externas (sucias y enfermas).

9 Nos referimos al Ejército Revolucionario del Pueblo (ERP), estructura militar del Partido Revolucionario de los Trabajadores (PRT), que se radicó en la selva de la provincia del Tucumán, en el norte argentino, a principios de los años setenta, con el objetivo de iniciar un “foco" en la región. Luego, en 1975, por decreto presidencial de María Estela Martínez de Perón, las fuerzas armadas (ejército y fuerza aérea) llevan a cabo el "Operativo Independencia”, destinado a eliminar al ERP.
} 
mia y a los cuales se extendería progresivamente, determinó semánticamente la identificación de un “origen” o zona de concentración del mosquito, y posteriormente la descripción de su "avance" hacia otras áreas. Se distinguieron relatos que fomentaron la representación de un Otro no nacional (o incluso nacional, pero fronterizo con los países limítrofes del norte), que "traía" a la ciudad -inoculado en su cuerpo- al virus. Ese "Otro" (extra)nacional fue identificado en varias noticias como ciudadanos de Bolivia y Paraguay.

Posteriormente, cuando se asumió que los casos de dengue también emergieron nacionalmente, la noción de frontera que el periódico comienza a trazar, es ya nacional pero con una importante diferenciación interprovincial. El dengue se acerca a Córdoba desde "el norte", una delimitación algo imprecisa que busca dar cuenta de aquellas áreas que tienen similitudes no sólo climáticas sino socioculturales con los países limítrofes, como Catamarca, Chaco, Formosa y Jujuy.

La información da cuenta de un pico en la aparición de casos extraprovinciales, entre el 14 y el 16 de abril. Recién a partir del 17 de abril, se dio la confirmación oficial del primer caso denominado "autóctono", o sea, de personas que habían contraído la enfermedad en la ciudad de Córdoba. Lo anterior representó el momento en que se asumió que el vector ya circulaba en la región. A partir de esa fecha, las fronteras se volvieron porosas y las noticias se concentraron en describir la epidemia en el ámbito de la ciudad de Córdoba. Para entonces, las descripciones de tipo geográfico acerca del avance de la enfermedad en Córdoba se instalaron como un proceso progresivo, donde los casos fueron avanzando "de norte a sur" y emergieron en la ciudad distribuidos por barrios.

Nos parece de sumo interés resaltar la funcionalidad que en la descripción del periódico tuvo la conformación de zonas de riesgo y no riesgo, a través de las cuales se pretendieron determinar los recorridos "convenientes e inconvenientes". Sin embargo, como se aprecia en las noticias seleccionadas, dichas áreas fueron reduciéndose con el paso de los días, desde un área internacional, luego interprovincial, hasta configurarse una suerte de mapa barrial, con zonas "rojas" que indicaron la mayor presencia de casos de dengue en la ciudad. El resultado se plasmó en la diagramación de una especie de mapa epidémico "paralelo" que construyó LVI, lo que permitió al lector conocer la nueva configuración geográfica local de la epidemia, como puede verse en los mapas de más abajo (Ilustración 1 y 2).

\section{El dengue como error o sorpresa}

La presencia del dengue en territorio argentino fue resaltada por el diario como un acontecimiento inédito, e incluso los propios cordobeses lo describieron como una enfermedad poco conocida ${ }^{10}$, tanto en su sintomatología como en su forma de adquisición.

Hasta la emergencia de la epidemia, el imaginario local relacionaba este padecimiento con las zonas cálidas de países limítrofes o el norte de Argentina, áreas no casualmente asociadas también con la pobreza:

- "El médico aclaró que la mujer que estaría afectada "no ha sido expuesta en otras zonas endémicas o epidémicas". (LVI 03/o4/o9)

- "Ocaña argumentó en el Congreso que el brote de dengue que sufre la Argentina tiene directa relación con las epidemias de los países vecinos, Bolivia y Paraguay, como si el "contagio" hubiera sido inevitable" (LVI o9/o4/og)

- Comenzó la Semana Santa y el destino "elegido" por muchos habitantes de la ciudad de Córdoba es el norte del país. ¿No es esto un acto de irresponsabilidad de los cordobeses y de quienes pernoctan en nuestra ciudad? (LVI 11/o4/og)

- Y eso es lamentable, porque significa que la ciudad no está preparada para enfrentar un brote de dengue" (LVI 24/04/og).

Nos parece interesante resaltar la frecuencia con que los cuerpos de las noticias insistieron en enunciar el desconcierto por la aparición del flagelo en la provincia de Córdoba. De esta manera, la asociación entre la falta de antecedentes de este tipo de padecimiento se asoció, con más fuerza durante la primera quincena de abril, a una suerte de justificación acerca de la ignorancia de la población sobre

10 El o1 de abril LVI publicó una encuesta hecha entre sus lectores on line donde se dice que el 38,4\% de éstos respondieron que tenían dudas sobre cuáles eran los síntomas del dengue. (LVI o1/o4/og). 
las formas de prevención que el dengue requirió. El "factor sorpresa" contribuyó a generar una especie de impunidad en el accionar ignoto de la población, que no parece, sin embargo, suficiente para disculpar al Estado en sus faltas, tal como observaremos más adelante.

\section{El dengue como re-distribuidor de riesgos}

Si bien inicialmente las representaciones que los cordobeses tenían sobre el dengue respondieron a una idea de una enfermedad exportada de sectores pobres y alejados, a medida que la epidemia avanzó, dicha representación fue transmutándose.

Cuando la epidemia se instaló en la ciudad de Córdoba, esta categoría abarcó a la enfermedad como un fenómeno que "democratizó" el impacto del padecimiento, o re-distribuyó el riesgo de padecerlo. Al contrario de la anterior vinculación del dengue con una "enfermedad de la pobreza" únicamente, este padecimiento se resignificó y pasó a concebirse como una enfermedad a la que "todos están expuestos”. Cobró importancia la cuestión de las piscinas de zonas residenciales como focos de reproducción del vector, y no solamente los reservorios de agua del resto de la ciudad (charcos, cacharros, etc.) en los lugares con menores condiciones de infraestructura.
De la misma manera, las acciones preventivas se extendieron a toda la población, y paralelamente a que se advirtió sobre la necesidad del "descacharramiento" en las viviendas de toda la ciudad, las piscinas de residencias particulares comenzaron a ser cuestionadas por ser potenciales reservorios de larvas de mosquitos.

El periódico local, a través de la enumeración de los casos que paulatinamente aparecieron en diferentes zonas de la ciudad de Córdoba, fue construyendo -como anticipamos- una suerte de "mapa del dengue", a través del cual ubicó a los enfermos con diagnóstico clínico en lugares precisos. Así, la epidemia tuvo desde su inicio, un asidero en lo geográfico, posible de identificar a través de la enunciación de los llamados "barrios más afectados". Como sugerimos anteriormente, si bien esto significó en primera instancia la categorización de los barrios según el riesgo que representaban para sus habitantes, para fines del mes de abril quedó claro que la ciudad en su totalidad constituía una “zona de riesgo". De alguna manera, la extensión del alerta a todos los barrios generó una especie de “democratización del riesgo" que no era tal al inicio de la epidemia, momento en que los barrios seña-

Ilustración I (izq.) "Las zonas en sospecha" de dengue autóctono (LVI 08/04/09) Ilustración 2: (der.) Dónde se localizan los 14 posibles casos de dengue autóctono ( $\mathrm{LVI}$ II/O4/09)
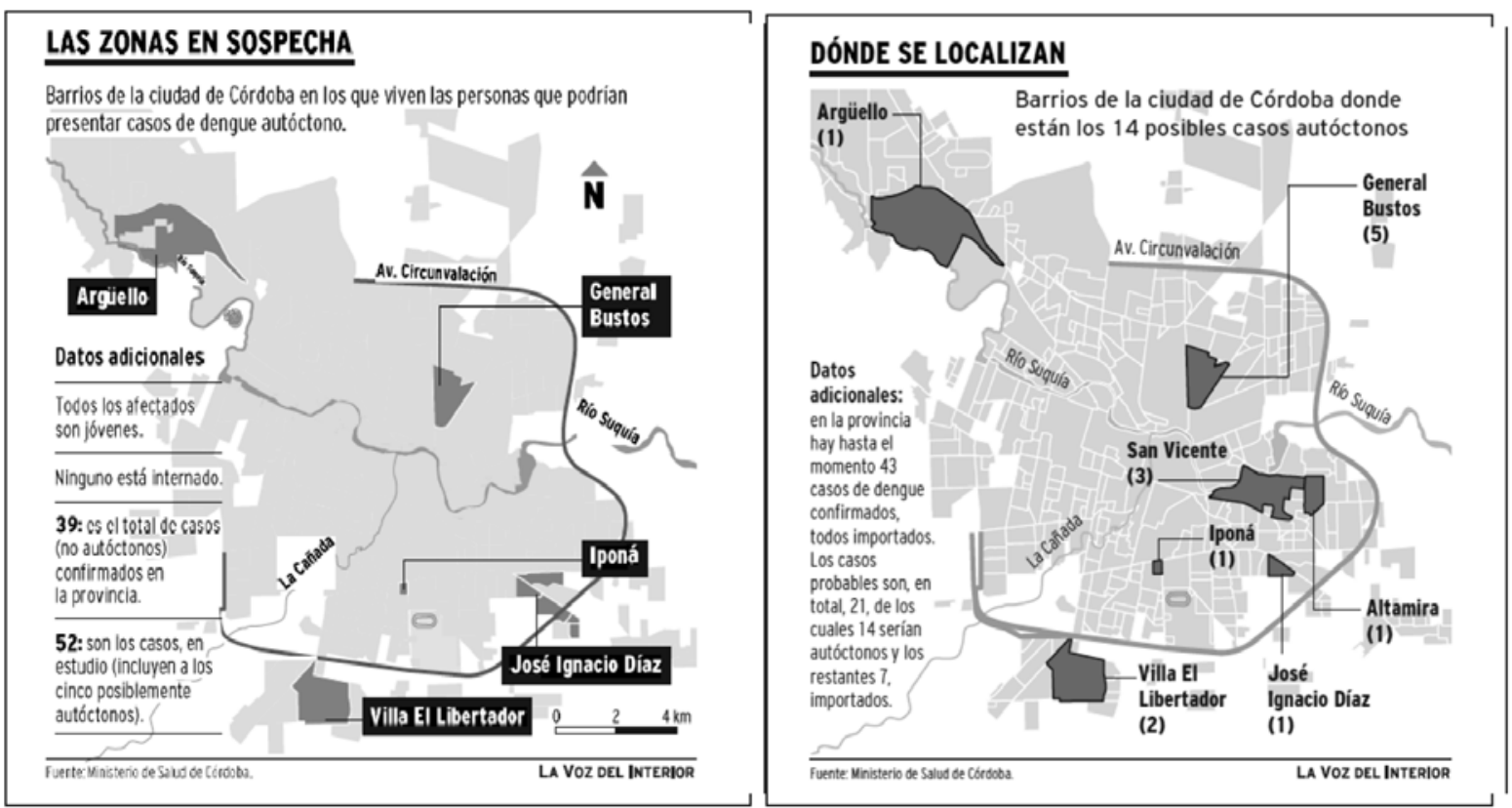
lados como riesgosos correspondían a los estratos socioeconómicos más bajos.

- "Las piletas domiciliarias, un riesgo serio" (LVI 07/04/og).

- "La Municipalidad de Córdoba anunció hoy que enviará recomendaciones sobre cómo prevenir el dengue a 13.200 propietarios de inmuebles que posean piscinas" (LVI o8/o4/og).

- "Familiares de Diego Bobatto confirmaron que la mamá del ex presidente de Instituto [Atlético Central Córdoba] presenta síntomas de dengue" $(10 / 04 / 09)^{11}$.

- [Habla la columnista de los viajes al norte y su "irresponsabilidad"] "Todos éstos son interrogantes que parecen no tener respuesta, y me preocupa el desarrollo de nuestro país si acciones tan irresponsables son tomadas por los argentinos frente a una peligrosa enfermedad que acecha a todos" (LVI 11/ abril/og).

- "Pero así como en la historia de Homero, todas las fortalezas amuralladas pueden sufrir su caballo de Troya, a veces también invisible. Pasa con la inseguridad. Pasó con el virus del SIDA, que desde la castigada África se desplegó por el mundo. Pasa, en estos días y entre nosotros, con el virus del dengue, la llamada "enfermedad de la pobreza": todo lo que no hicimos por el interior desolado, ni siquiera por sus pestes, ahora es una angustia que acosa a todos (provincias y Buenos Aires, pobres y ricos) con el zumbido de un mosquito" (LVI 12/o4/og).

\section{El rol del Estado}

\section{El rol del Estado como ACTIVO - reparador - pre- visor - eficiente}

Esta categoría fue significada básicamente en torno a dos variantes: el comportamiento del Estado, en sus formas de gobierno nacional, provincial y municipal, concebido como positivo por sostener acciones rápidas y eficientes, conducentes a minimizar los casos de dengue, su extensión y facilitar la atención de los mismos; o por el contrario, se identificó al
Estado en su rol negativo, al no accionar sobre la epidemia de forma adecuada.

Esta primera adjetivación del Estado en términos positivos lo describió como "reparador", en alusión a un agente que "mejoró" de alguna manera una condición indefectiblemente instalada como fue la epidemia. Intrínsecamente ambivalente, aludió a que el Estado antes fue negligente y luego buscó subsanar la inacción a través de acciones precisas. Paralelamente, se le describió como un Estado "previsor" en el sentido de proactivo, generador de acciones a través de las cuales se anticipó a la situación sanitaria que se avecinaba. Finalmente, las noticias describieron a un Estado "eficiente" cuando logró exitosamente lo propuesto.

Como destacamos antes, estas descripciones que se plasmaron en las noticias emitidas por LVI se distribuyeron diferencialmente entre los tres ámbitos de gobierno: nacional, provincial y municipal. Se advirtieron descripciones diversas para cada grado de responsabilidad gubernamental, organizadas en torno a lo que entendemos era una afinidad o enfrentamiento político del diario con el gobierno nacional, cuestión que está desarrollada más adelante.

En ocasiones, el Estado municipal apareció llevando a cabo actividades sanitarias exitosamente con la cartera de salud de la provincia, mientras otras veces se describió la relación municipio provincia como descoordinada. Es de destacar, sin embargo, que en un orden de jerarquía política LVI mostró al estado municipal como un actor más débil y superado por la coyuntura que presentó la epidemia, lo que en última instancia pareció constituirse como una atenuante de sus errores o inacciones.

El diario construyó, asimismo, una imagen del Estado provincial muy particular, caracterizándolo a través de la descripción pormenorizada de las actividades que éste llevó adelante para combatir la enfermedad, especialmente desde la cartera de salud. Una de las fuentes de información que resultó de permanente consulta fueron los funcionarios provinciales (área salud), a quienes LVI sostuvo en un rol de informantes claves y de autoridad en la enunciación del avance de la epidemia. Fue fre-

11 El diario publicó noticias equivalentes sobre el mundo de los famosos del fútbol (alto poder adquisitivo) cuando habló sobre la suegra de Saviola (12/o4/og) y el delantero argentino radicado en Ecuador, Martin Mandra (14/o4/og), ambos con síntomas de dengue. 
cuente encontrar reproducidas las críticas de los funcionarios locales (del municipio, pero sobre todo de la provincia) hacia el gobierno nacional, por su accionar equívoco ante el brote epidémico.

Cuando finalmente observamos la construcción que el periódico hizo de las actividades del Estado nacional, la imagen que se construyó fue diametralmente diferente a las anteriores. Mientras el gobierno provincial aparecía liderando tareas de forma activa (con alianzas intermitentes con la municipalidad), demostrando su preocupación por el avance de la enfermedad, el Estado nacional fue calificado como ineficiente, despreocupado y de alguna manera, negligente.

Veamos todo lo anterior a través de las citas:

-"En el marco de las medidas de prevención implementadas por el Ministerio de Salud, el viernes y sábado brigadas sanitarias integradas por alumnos de la Facultad de Medicina (de las universidades Nacional y Católica de Córdoba) y Escuela de Enfermería, junto a personal de centros vecinales y de la Secretaría de la Juventud, realizarán tareas de descacharramiento (eliminación botellas, neumáticos, latas, etcétera) en barrios del noreste de esta ciudad" (LVI 01/o4/o9).

•"En enero ya se sabía”. En Córdoba, a su vez, el titular de Salud de la Provincia, Oscar González, criticó en duros términos el manejo que se hizo con el dengue en la Argentina”. (LVI 03/o4/og).

-La Provincia y la Municipalidad de Córdoba comenzaron esta mañana a fumigar "cuadra por cuadra" en la zona noroeste de la ciudad (en Argüello) El operativo arrancó en CPC de Argüello, con la presencia del intendente Daniel Giacomino, el gobernador Juan Schiaretti y el ministro de Salud provincial, Oscar González" (LVI 13/o4/o9)

- "Las actividades consisten no sólo en las aplicaciones de larvicidas en los posibles focos infecciosos, sino también en el control de los espejos de agua, la entrega de folletería, y la realización de charlas didácticas" (LVI 15/o4/o9)

.Fumigan y visitan hogares y negocios" (LVI 22/4/9)

•"La explosión de la demanda motivó la habilitación, hace unos días, de dos consultorios de la guardia para atender con exclusividad a quienes llegan con temperatura alta. "Es muy probable que mañana (por hoy) o pasado estemos sumando otros consultorios más para responder a este aumento de consultas", adelantó Roland. 12" (LVI 17/4/og)

- "Así, los contagios sospechosos son tratados como si estuvieran confirmados, tanto en lo relativo a la atención médica, como a las acciones que se desarrollan para bloquear el foco" (LVI 15/o4/og)

- "A causa de la incesante demanda, el Hospital Rawson duplicó la cantidad de consultorios abocados a atender a los pacientes que llegan con síntomas compatibles con dengue". (LVI 18/o4/og)

- "Durante el encuentro, el funcionario admitió que “estamos viendo la punta del iceberg”, en función de la locación geográfica de Córdoba respecto al país, y agregó que "no hay que ocultarlo". (LVI 17/o4/og)

- "Dengue: la Provincia emitirá un programa televisivo: La iniciativa tiene como fin informar a la población de Córdoba sobre "las recomendaciones a tener en cuenta” para frenar la transmisión de la enfermedad" LVI (18/o4/o9)

-"Ministro de la Provincia de Córdoba: reunión con 300 intendentes, jefes comunales y directores de hospitales del interior" (LVI 23/o4/o9)

\section{El rol del Estado como INACTIVO - negligente - abandónico - ineficiente}

Esta categoría aglutinó los aspectos negativos relativos al Estado. La inactividad se refirió a la falta de acciones, o a la acción por omisión. La negligencia hizo alusión a irresponsabilidad, al incumplimiento de las obligaciones; abandónico se refirió a la desidia, a la falta de compromiso y a la ausencia estatal; la ineficiencia, al incumplimiento de los compromisos inherentes al Estado.

Como adelantamos, las noticias del período reprodujeron reclamos específicamente dirigidos al Estado nacional y sus funcionarios, fundamentalmente a la entonces Ministra de Salud de la Nación, Graciela Ocaña. Las demandas locales hacia la nación incluían el pedido de recursos específicos para el freno de la epidemia, e incluso se instaló la

12 El Dr. Hugo Roland es Director del Hospital Rawson, dependiente del gobierno provincial. 
sospecha acerca del grado de responsabilidad que le cabía a los funcionarios nacionales, quienes en un supuesto accionar "negligente", no previeron ni evitaron el arribo de la enfermedad. En el mismo sentido, se plantearon críticas referidas a la carencia de legislación específica referida al tema epidemiológico, que permitieran ejecutar acciones de planificación, prevención y promoción tendientes a reducir el impacto de la enfermedad. En otras palabras, se cuestionó la ausencia del Estado nacional al frente de políticas previsoras de una situación que, desde las noticias publicadas por LVI, se pensaba como evitable.

Podemos dejar planteada, como hipótesis que requiere de profundización, lo que evidenciamos como una relación conflictiva entre la línea editorial de LVI y el Estado nacional, producto quizás de la pertenencia de dicho periódico a un grupo de multimedios como el que conforma Clarín.

Dicha empresa sostiene desde los últimos años una postura más afín a los argumentos de sectores de la oposición política que cuestionan el accionar del gobierno en muchos ámbitos, por lo que la crítica a las medidas sanitarias es uno más de los aspectos que se discuten. En términos empresariales, LVI pertenece al Grupo Clarín desde que se efectivizara la operación de control del matutino cordobés, a través de la compra por el Grupo CIMECO (Compañía Inversora de Medios de Comunicación) de las acciones que le pertenecían al diario La Nación -el socio saliente-, por unos 62 millones de pesos, en el $2008^{13}$. De esta forma, LVI pareció sumarse a la línea editorial que sostenía el tradicional periódico de Buenos Aires “Clarín”, en un constante enfrentamiento con el gobierno nacional. Se advirtió en 2009 cierta cercanía entre LVI y el gobierno de la provincia de Córdoba, posiblemente fomentada por la adhesión al reclamo de la provincia a la nación para que cumpliera con la entrega de fondos de la Coparticipación Federal, y por la postura del Gobernador Schiaretti en contra de las retenciones a la soja que proponía el Ejecutivo Nacional (a través del decreto 125/o8), motivo de arduos conflictos durante 2008 y 2009 . Finalmente, en referencia a la relación entre LVI y el Gobierno de la
Municipalidad de Córdoba durante 2009, podemos, a grandes rasgos, describirla como una relación que no fue cercana. Las mayores críticas del periódico al manejo de la epidemia y la situación sanitaria fueron para la nación y luego para el municipio de la ciudad de Córdoba. Podemos conjeturar lo anterior como cercanía política, puesto que en dicho período el Municipio se identificó con el Ejecutivo Nacional más que con el Gobierno provincial.

Grafiquemos lo anterior con la voz del periódico: - "A fin de enero, cuando tuvimos la información de que en Córdoba en un mes había habido más casos que en 10 años, advertimos que estaba pasando algo anormal, y en lugar de ocultarlo, como hicieron otros, iniciamos las acciones sanitarias para concienciar a la población", dijo. "Y si nosotros lo advertimos a más de mil kilómetros del centro del problema, es incomprensible, temerario o una notoria ineficiencia no haber hecho nada en ese lugar", fustigó el Ministro de Salud [de la provincia]. (LVI 03/04/o9).

- La Defensoría del Pueblo de Córdoba anunció hoy que solicitó a diversos organismos de la Provincia y a la Municipalidad que "adopten las medidas necesarias" para la "limpieza y el mantenimiento" de los canales de la ciudad "a fin de garantizar la seguridad, salubridad y calidad de vida de los habitantes", en especial ante la amenaza del dengue" (LVI 06/o4/og)

- La situación del dengue en Argentina se "descontroló" por el "fracaso en la prevención y el control" de la enfermedad, según organizaciones civiles que denunciaron la existencia de 20 mil casos" (LVI o8/o4/og)

- "Crece el descontento de los barrios del noroeste por la inacción estatal” (LVI o9/o4/og)

- "Dengue: Córdoba pidió a Ocaña una reunión urgente" (LVI 09/04/o9)

- “Así, en 2007 Nación habría aplicado 13 millones de pesos a mantener el mosquito a raya. Y en 2008 sólo fueron cinco millones”. (LVI o9/o4/og)

- "Desencuentro [entre municipio y provincia] por la fumigación casa por casa” (LVI 10/o4/o9)

13 Fuente: Diario Critica de la Argentina, en su versión digital del 2 de Marzo de 2010, Año 1, Edición 723. Disponible en: <http://www. criticadigital.com.ar/impresa/index.php?secc=nota\&nid=2290>. Acceso en: 12 mayo 2010. 


\section{Los (potenciales) afectados}

\section{Los (potenciales) afectados como responsables}

En esta tercera y última dimensión analizada, la de los afectados, evidenciamos cómo se construyó mediante descripciones pormenorizadas, la situación de las reales y potenciales víctimas de la epidemia de dengue.

En esta categorización de "responsables", se indican aquellas significaciones que colocaron a los habitantes de la ciudad como actores conscientes de la situación sanitaria por la que atravesaban, bien informados y accionando conforme a las recomendaciones públicas de forma comprometida. Se describió a la ciudadanía como agentes colaboradores de las acciones encabezadas por el estado provincial y municipal, paralelamente invitados por el gobierno y los medios a colaborar en las acciones preventivas, permitiendo el ingreso de los fumigadores, eliminando las fuentes de reproducción del mosquito e informándose de las medidas de prevención:

- "Aída Merlo (79) fue la primera vecina de Alto Alberdi en dejar entrar a su casa a médicos afectados a la campaña para prevenir la propagación del dengue a través de la eliminación de cacharros casa por casa" (LVI 04/04/o9)

- "La acción de la comunidad es esencial en la lucha contra el dengue”, aseguró el experto mejicano Adolfo Martínez-Palomo. "En México la gente recibe de muy buena gana y ve con buenos ojos a las brigadas que van casa por casa a eliminar los cacharros que puedan ser criaderos de mosquitos”, indicó, y dijo que su país cuenta con la experiencia previa de haber tenido que combatir el paludismo. "Es el método cubano, y ha demostrado ser el más efectivo”, indicó. (LVI o9/o4/o9).

- "Ávila Vázquez (Subsecretario de Salud municipal), explicó que se irá informando un cronograma de las fumigaciones casa por casa y solicitó a los vecinos que permitan el ingreso de las patrullas" (LVI 11/o4/og)

- "Pero tiene que quedar totalmente claro que fumigar no es suficiente para combatir el dengue, porque eso sólo elimina los mosquitos adultos, pero no las larvas. O sea que cada familia debe hacer, sí o sí, el descacharrado de su casa, para eliminar los criaderos" (LVI 11/o4/o9)
- "El Estado puede hacer una parte con las fumigaciones y con las campañas, pero la gente tiene que tomar conciencia que hay que descacharrar", dijo el intendente Giacomino. (LVI 13/o4/o9)

- "Es importante que todos sigamos dando la batalla contra del dengue para que no se transforme en una epidemia”, señaló el gobernador Juan Schiaretti (LVI 13/04/o9)

La apelación a la auto-responsabilidad de la población en el control de la epidemia fue constante y se traslució en el intento por instalar en la opinión pública la idea de que el freno a la epidemia era una acción conjunta que debía encararse entre gobierno y ciudadanía. El gobierno accionó en ámbitos públicos, mientras la ciudadanía debió colaborar a través de acciones sobre la esfera privada-doméstica.

\section{Los (potenciales) afectados como víctimas del Estado}

Semánticamente, se alude con la adjetivación de afectados, a aquellos actores que personalmente se enunciaron como abandonados por la (in)acción estatal. Dentro de esta categoría entraron todos los ciudadanos que de alguna u otra manera reclamaron mediante protestas de diversa índole por más presencia del Estado, denunciando su inacción y desidia. El mayor espacio editorial fue destinado a cubrir las demandas de los habitantes de barrios afectados por la aparición de los primeros casos de dengue, quienes reclamaban que no se estaban aplicando en su zona las medidas de recaudo necesarias para evitar la propagación de la epidemia. Este espacio también fue aprovechado por los habitantes para denunciar incumplimientos previos del Estado, acciones que de haberse desarrollado en tiempo y forma podrían haber minimizado el impacto de la epidemia.

- "Vecinos de barrio Empalme cortaron media calzada de avenida Sabattini en reclamo de fumigación". (LVI 15/4/og)

- "El titular del centro vecinal de Cerro Norte, Enrique Rodríguez, expuso varios problemas irresolutos: calles inundadas por falta de desagües y otras en pésimo estado, falta de iluminación, lagunas de agua estancada en tiempos en que el dengue es una amenaza y escasez de líneas del transporte". (LVI og/o4/og) 
- "Cuando llegue el frío, la epidemia se autolimitará y varios sectores del Gobierno se acreditarán este éxito de gestión, pero lo cierto es que miles de personas (por cada caso clínico de dengue hay por lo menos cinco subclínicos) quedan con su vida hipotecada" (LVI 10/o4/og).

\section{Los (potenciales) afectados como precavidos - ignorantes}

Los potenciales afectados, incluidos en esta categoría, fueron descritos por LVI como unos agentes previsores en exceso y con miedo, resultado de la desinformación y el desconocimiento con respecto a la enfermedad del dengue. Estas personas fueron descritas como aquellos que sobredimensionaron el peligro e impacto de la enfermedad, contribuyendo con sus expresiones a la generación de una sensación de desprotección y exposición al peligro. Asimismo, se les responsabilizó de que a través de sus acciones basadas en el desconocimiento, pusieron su salud y la de los demás en riesgo, a través de dos conductas particulares: quienes transitaban por áreas previamente determinadas como "de riesgo" accionaron en forma negligente. Por otra parte, quienes no colaboraban con las tareas de prevención -eliminación de espacios con agua donde se pueda reproducir el mosquito- atentaban contra sus pares.

- "De las 1.125 personas que respondieron a la pregunta de si conocían los síntomas, el 38,4 por ciento dijo: "No, tengo dudas sobre ellos". El resto aseguro conocerlos". (LVI 01/04/o9)

- "Mi hija me dijo así nomás qué era esto del dengue pero no sé nada de la enfermedad. Me parece bien que estos chicos vengan y me digan qué tengo que hacer para que no me piquen los mosquitos. Es bueno recibir información para prevenirse". (LVI 04/04/og)

- "Pedro deja las gomas llenas de agua en el patio de su casa, pero no le importa, porque no sabe que eso atrae mosquitos. Andrés nunca vació la pileta, pero no le importa, porque sin agua se resquebrajarían las paredes azules...” (LVI 12/o4/og)

- "Espirales, insecticidas, repelentes y tabletas. Por temor al dengue, la gente ha vaciado las góndolas de los productos "antimosquitos" en los principales supermercados de la ciudad de Córdoba. En los hipermercados, algunos compraban en grandes cantidades para abastecer las despensas de los barrios. Muchos se quejaron por la falta de productos y por los precios, aunque igualmente llevaban los productos" (LVI 12/o4/og)

\section{Consideraciones Finales}

A partir del anterior análisis, podemos decir que la epidemia estudiada constituyó, al igual que otras enfermedades emergentes como la gripe A H1N1, un fenómeno con un amplio impacto social, y como tal, los medios de comunicación intervinieron en la generación de información respecto a un hecho de esta envergadura. Nuestro trabajo pretendió acercase a la forma en que el periódico LVI construyó una serie de imágenes particulares que en mayor o menor medida, impactaron en la subjetividad de la sociedad cordobesa.

El dengue, como enfermedad, fue asumido en gran parte de las noticias analizadas como un enemigo al cual vencer, haciendo constante uso de un vocabulario que vinculó aspectos médicos y militares, específicamente tomados del universo conceptual en torno a la guerra de guerrillas y posicionando al flagelo como un canal a través del cual vehiculizar toda una serie de representaciones y mensajes hacia el Estado en sus diferentes esferas, hacia la ciudadanía y la otredad, entre otros temas rastreables a la hora de analizar discursos en torno a esta enfermedad. En gran medida también, la enfermedad se asumió en las páginas del diario como un hecho sin antecedentes en nuestra región, fenómeno que contribuyó a acrecentar aún más la sensación de indefensión de los ciudadanos al enfatizar que este tipo de enfermedades les ocurre "a Otros".

Al construir las noticias, el periódico pretendió diferenciar y separar las funciones del Estado en sus niveles municipal, provincial y nacional, posibilitando así a la atribución de responsabilidades diferenciales para cada plano gubernamental. Esto hizo posible construir con cada uno de estos espacios de gobierno una relación diferente, que se 
reflejó en la valoración de las acciones desarrolladas por el gobierno de la provincia, en desmedro del accionar de la nación: mientras el estado provincial y sus funcionarios fueron constantemente conceptualizados a través de adjetivos positivos, el gobierno nacional recibió las mayores críticas en torno a su incapacidad para enfrentar la epidemia, seguidos por el gobierno municipal.

Con relación a la construcción de una serie de imágenes de los (potenciales) enfermos, el medio de comunicación fue consecuente con la cartera de salud provincial y sus campañas de prevención, asumiendo en sus páginas una conducta prescriptiva para con los lectores, apelando paralelamente a la auto-responsabilidad ciudadana en el control de la epidemia. Esto redujo el espacio disponible para que los ciudadanos se ubicaran como sujetos victimizados por la ausencia estatal, y sus demandas tuvieron poco espacio en las noticias. La voz legitimada, en cambio, fue la de los científicos, quienes se constituyeron en los referentes de consulta obligatoria a medida que avanzaba la enfermedad.

Finalmente, el presente trabajo ha sido así un acercamiento sociológico al fenómeno del accionar de los mass media frente a situaciones de crisis sociales vinculadas a epidemias, en una época en que la población en general se ve enfrentada a la emergencia de enfermedades con las que se toma contacto en primera instancia a través de los medios de comunicación.

\section{Referencias}

ALCALAY, R. La comunicación para la salud como disciplina en las universidades estadounidenses, Revista Panamericana de Salud Pública, Washington, D.C., v. 5, n. 3, p. 192-196, mar. 1999.

ARGENTINA. Secretaria de Planificación en Salud. Médicos del Mundo - Argentina. Epidemia de dengue en Argentina: determinantes sócioeconómicos, ausencia del Estado y opacidad epidemiológica. Ciudad de Buenos Aires: MDM, 2009. Disponible en: <http://www.mdm.org.ar/ informes/12/Epidemia-de-DENGUE-en-Argentina. pdf $>$. Acceso en: 22 mayo 2009.
ARGENTINA (República). Ministerio de Salud de la Nación. Enfermedades infecciosas: Dengue. Diagnótico de Dengue. Guía para el equipo de salud. 2. ed. Buenos Aires: Ministerio de Salud de la Nación, 2009. Disponible en: < http://www.msal. gov.ar/htm/site/pdf/guia-dengue.pdf $>$. Acceso en: 24 jun. 2009.

CABALLERO HOYOS, R. et al. Concepciones culturales sobre el dengue en contextos urbanos de México. Revista de Saúde Pública, São Paulo, v. 40, n.1,p. 126-133, fev. 2006. Disponible en: <http://www.scielosp.org/scielo.php?script=sci arttext\&pid=So034-89102006000100020 > Acceso: 18 jun. 2009 .

CAPONI, S. Coordenadas epistemológicas de la medicina tropical. História, Ciências, Saúde Manguinhos, Rio de Janeiro, v. 10, n.1, p. 113-49, jan.-abr. 2003.

CARBONETTI, A. Enfermedad y sociedad: la tuberculosis en la ciudad de Córdoba 1906 y 1947. Córdoba: Editorial de la Municipalidad de Córdoba, 1999.

FORNI, F. Estrategias de recolección y estrategias de análisis en la investigación social. In: FORNI, F.; GALLART, M.; VASILACHIS, I. Métodos cualitativos II. La práctica de la investigación. Buenos Aires: Centro Editor de América Latina, 1993.

GLASER, B.; STRAUSS, A. El método de comparación constante de análisis cualitativo (traducción s/d). In: GLASER, B.; STRAUSS, A. The discovery of grounded theory: strategies for qualitative research. New York: Aldine Publishing Company, 1967. cap. 5 .

GUEVARA, E. La guerra de guerrillas. España: Argitaletxe Hiru, 1997.

MASSARANI, L.; BUYS, B. La ciencia en la prensa de América Latina: un estudio en 9 países.In: REUNIÓN DE LA RED DE POPULARIZACIÓN DE LA CIENCIA YA LA TECNOLOGÍA EN AMÉRICA LATINA Y EL CARIBE, 10. (RED POP UNESCO), y TALLER “CIENCIA, COMUNICACIÓN Y SOCIEDADE”. San José, Costa Rica, 2007. Disponible en: <http://www.cientec.or.cr/ pop/2007/BR-LuisaMassarani.pdf $>$.Acceso en: 4 jun. 2009 . 
MOSQUERA, M. et al. Comunicación, movilización y participación: lecciones aprendidas en la prevención y control de la fiebre dengue (FD). Investigación y desarrollo, Colombia, v. 14, n. 1, 2006. Disponible en: <http://ciruelo. uninorte.edu.co/pdf/invest_desarrollo/141/5_Comunicacion,\%2omovilizacion\%20y\%20 participacion.pdf>. Acceso en: 18 jun. 2009.

SONTAG, S. La enfermedad y sus metáforas.

Buenos Aires: Taurus, 2003.

SUTTER, P. Arrancarle los dientes al trópico: ambiente, enfermedad y el Programa Sanitario de Estados Unidos en Panamá, 1904-1914. Papeles de Población, Toluca, México, n. 24, p. 61-93, abriljunio 2000.

YUNI, J.; URBANO, C. Mapas y herramientas para conocer la escuela: investigación etnográfica e investigación - acción. Córdoba: Editorial Brujas, 1999. 